\title{
1-Phenyl-1H-tetrazol as Corrosion Inhibitor for Pipeline Steel in Sulfuric Acid Solution
}

\author{
Shiying Tao ${ }^{1,2,3 \text {, }}$ \\ ${ }^{1}$ Faculty of Science and Engineering, The University of Nottingham Ningbo China, Ningbo 315100 , \\ PR China \\ ${ }^{2}$ Ningbo Nottingham New Materials Institute Ltd., Ningbo 315040, PR China \\ ${ }^{3}$ School of Materials and Chemical Engineering, Ningbo University of Technology, Ningbo 315211, \\ PR China \\ *E-mail: sytao_nbu@163.com, Carey.Tao@nottingham.edu.cn
}

doi: $10.20964 / 2021.03 .49$

Received: 15 November 2020 / Accepted: 6 January 2021 / Published: 31 January 2021

1-Phenyl-1H-tetrazol (PHT) has been studied as an efficient corrosion inhibitor for X65 steel in sulfuric acid corrosion environment. Atomic force microscope test results show that PHT can effectively inhibit the corrosion of X65 steel in $0.5 \mathrm{M}$ sulfuric acid solution. Quantum chemical calculations and molecular dynamics simulations show that PHT has a small energy gap value and a large dipole moment value, which is an excellent corrosion inhibitor. In addition, the adsorption of PHT on the Fe(110) surface adopts parallel adsorption and a large binding energy value, which shows that PHT can effectively inhibit the corrosion of X65 steel. Potentiodynamic polarization test results show that as the PHT concentration increases, the value of the corrosion current density decreases significantly. When the PHT concentration is $1 \mathrm{mM}$, the corrosion inhibition efficiency can reach $92.1 \%$. In addition, the adsorption of PHT on the surface of X65 steel conforms to Langmuir adsorption, and the adsorption process is spontaneous.

Keywords: Corrosion inhibitor, X65 steel, Molecular dynamics simulation, Quantum chemical calculation, AFM

\section{FULL TEXT}

(C) 2021 The Authors. Published by ESG (www.electrochemsci.org). This article is an open access article distributed under the terms and conditions of the Creative Commons Attribution license (http://creativecommons.org/licenses/by/4.0/). 